\title{
From an Institutional Sport to a Street Sport: Street Football as a Negotiated Social System
}

\author{
Fayza Ayed ${ }^{1,2}$, Tesnim Hamdi ${ }^{2,3}$, Zouheir Ben Jannet ${ }^{2,4}$ \\ ${ }^{1} \mathrm{PhD}$ Student at the Higher Institute of Sport and Physical Education of Ksar Said, University of Manouba, Manouba, Tunisia \\ ${ }^{2}$ Member of the Research Unit: State, Culture and Mutations of Society, University of Sfax, Sfax, Tunisia \\ ${ }^{3}$ Assistant at the Higher Institute of Sport and Physical Education of Gafsa, Gafsa, Tunisia \\ ${ }^{4}$ Lecturer at the Faculty of Arts and Humanities of Sfax, University of Sfax, Sfax, Tunisia \\ Email: faizaayed89@yahoo.fr, tassou.hamdi@yahoo.fr, benjannet2004@yahoo.fr
}

How to cite this paper: Ayed, F., Hamdi, T., \& Jannet, Z. B. (2019). From an Institutional Sport to a Street Sport: Street Football as a Negotiated Social System. Advances in Applied Sociology, 9, 421-430. https://doi.org/10.4236/aasoci.2019.99031

Received: May 20, 2019

Accepted: September 9, 2019

Published: September 12, 2019

Copyright $\odot 2019$ by author(s) and Scientific Research Publishing Inc. This work is licensed under the Creative Commons Attribution International License (CC BY 4.0).

http://creativecommons.org/licenses/by/4.0/

\begin{abstract}
Objectives: Our work, consists in analyzing, in terms of initiation to the negotiation and mastering violence, the socialization process of the street football that presents a widespread phenomenon between the children and the adolescent in the various neighborhoods in Gafsa. Material and Methods: In order for our hypotheses to be checked empirically, we made use of the observation as method of investigation and we strengthened that observation by interviews. Furthermore, we performed observations sessions in six neighborhoods in Gafsa city to observe the games played in terms of regulation, relation with others, locations of practice, time, equipment, arbitration, measurement of the violence degree, and types of reactions against aggressions. Results: Our results show (demonstrated) that street football practice affects the socializing process of the adolescent who practices this kind of sport. As a result young people learn how to negotiate and how to master violence. Conclusion: The street football plays an educational role and affects positively the socialization process.
\end{abstract}

\section{Keywords}

Street Football, Socialization Process, Negotiation, Social Violence, Mastery of Violence

\section{Introduction}

Sport is a phenomenon which occupies afocal place in all fields of the social life. For this reason, sociologists tend to consider sport as "a total/complete social fact" (Mauss, 1997), in which all the social institutions intervene. Henceforth, this phenomena has become widespread according to a myriad of forms which 
have made of it a subject matter around which sociologists have raised questions related to its appearance, its forms, its principles, its values and other questions about the phenomena related to sport like socialization, integration, discrimination, exclusion and violence. Nevertheless, the complexity of sport and the diversity of the phenomena which are linked to it have made of it a hard-defined concept and have even become paradoxical. This paradox lies essentially in the various studies that have studied its emergence and its forms.

In this respect, some authors think that sport is a universal phenomenon. Its appearance goes back to the Antiquity. Henri-Irenée Marou considers sport as "a set of practices which contribute to the physical education of the Greek youth" (Marrou, 2001). Some other authors see that the sport's appearance and evolution are linked to the modern and industrial society in particular England during the XIX ${ }^{\text {th }}$ century (Parlebas, 1986). The same idea has been shared by Jean-Marie Brohm who relates the modern sport appearance to the capitalist society. Brohm distinguishes the sport in the capital period from the antiquity because the socio-economic, historical and the corporal culture are completely different (Brohm, 1992). Within the same view, Norbert Elias and Eric Dunning locate sport emergence in the context of modernity and they differentiate between the Greco-Roman period traditional games and the modern sport that appeared in the XIX ${ }^{\text {th }}$ century (Elias \& Dunning, 1986).

The first sport sociologists agreed on the institutional aspect of sports that distinguishes it from other forms of physical activities (Parlebas, 2012; Elias \& Dunning, 1986) ${ }^{1}$. However, other authors criticized this institutional definition because it reduces sports to a unique form (Duret, 2008; Marchiset, 2003; Brohm, 1992). Many sociologists noted different types of sports called non-institutional, informal, non-federal, and street sports (Gasparini \& Marchiset, 2008). These categories adopt other non-institutional forms of organization and allow athletes to form their own sport activity outside institutions and organize it autonomously and efficiently.

This article aims at first to study the way street football helps in the process of youngsters mediation and socialization in the city of Gafsa despite the self-organized and informal aspect. The second aim is to study the way athletes succeed in managing violence and commitment to sports.

\footnotetext{
${ }^{1}$ Parlebas estimates that the birth and the evolution of sport are related to the modern industrial society and especially England in the sixth century. In fact, the sport according to him before all is an engine that starts the corporal activities of the practitioners. This situation is also dominated by rules defining the competition that will determine winners and losers. Finally, and this what makes a big part of its sociological identity, the sport is an institutional action. It means an action allowed by official authorities especially federations and the state. Norbert Elias and Eric Dunning put the publication of sport in the modernity's context and distinguish between the traditional games of the antique Greek-Roman era and the modern sports appeared in the sixth century. Also, by including the sport in the civilization's process, he distinguished between the modern sport and the antique games and the war confrontations of the Greek-Roman period and the middle age. In fact, in logic of pacification, modernization and civilization, he defined the sport as rivalries that occur according to determined rules in an official way and in the framework of the institution, in contrary to antique combats that end by the death of one of the practitioners.
} 


\section{Materials and Methods}

Street football is a social system made by individual and collective actors who share the same goal. They coordinate and use negotiation methods that allow them to play football and sustain peace essential to overcome disagreements.

There was an investigation based on the observation of six famous neighborhoods in the city of Gafsa. ${ }^{2}$ It was an open observation during which 47 sport encounters were held in more than 4000 minutes. Street football games were registered and analyzed. The youngsters who participated in matches were interviewed. The total number of young participants observed during the six months of the investigation is presented in Table 1. It was 628 participants who were chosen in an arbitrary way. Their ages vary from 12 to 18 years.

The observation was direct, open and without our participation. We needed to introduce ourselves since girls' participation may cause some problems for the practitioners. Thus, our participation helps us to understand this phenomenon and all the related subjects. The observation started in the second semester of the year 2013 and continued until January 2014 to record more than 4000 minutes of observation.

Our observation worked on two main axes. At first, we tried to describe the practitioners' behaviour and the way games are organized mainly in terms of negotiation. Then, we tried to measure the violence level that may happen during matches. In fact, we made distinction between symbolic violence, verbal violence, and physical violence. Reactions to these types of violence can be symbolic, verbal, physical and also passive showing mastery of reaction or neutrality. This helps to identify the relation between every type of violence and the corresponding reaction.

\section{Discussion of Results}

\subsection{Street Football as a Negotiated Space of Socialization}

Street football is a widespread phenomenon in the different neighborhoods of

Table 1. Study population.

\begin{tabular}{cccc}
\hline Neighborhoods & Number of practitioners & Age & Sex \\
\hline Ras El Kef & 124 & & \\
Elksar & 95 & & \\
BébEraml & 99 & $12-18$ years & masculine \\
"Youth" neighborhood & 118 & & \\
Elhamila & 103 & & \\
"Sourour" neighborhood & 89 & & \\
Total & 628 & & \\
\hline
\end{tabular}

${ }^{2} \mathrm{Gafsa}$ is a city located in the south west of Tunisia. Its population is estimated by 137630 inhabitants according to the census of 2014, it comprises ksar. The observed neighborhoods are Raselkaf, Youth city, Elhamila, Sourour city, Bab Erraml and Ksar-Gafsa. 
Gafsa city. According to Parlebas, this activity is considered as a "sport game of street" and he defines it as "motor, entertaining and urban activities, sometimes new, sometimes imitative of the customary sports that create simple and fluctual rules keeping a great part of improvisation (basketball, football, hockey of street, roller...)". Therefore, the street sport is a space of socialization for the practitioners who are able to adapt the codes and the rules of institutional football to their own means (material, technical and human). Regarding this context, this adaptation is fulfilled/done following a negotiation process which is launched by the practitioners before the game. This negotiation covers the different aspects of the games: the rules, the space, the duration, the tools and the teams that are all the product of the negotiations between the actors.

As an informal space, street football finds its sport identity through compromises and agreements between actors who coordinate and fix negotiation methods that do not only determine the rules for the game but also the field, the equipment, the engines, etc.

\subsubsection{From Compromise to Contract}

The street football is an informal copy of the institutional football which functions/works within the framework of a federation which defines the rules, the arbitration and the discipline tools. Nevertheless, the practitioners do not faithfully apply these rules. Yet, they modify and adapt them according to the context. This adaptation is done through reflection, dialogue and in particular through negotiation. Therefore, the practitioners of the street football develop a compromise following a negotiation process to define the rules of the game, the space, the time, the tools and equipment. Thus, the street football finds its informal identity through the compromises and the agreements between the actors.

The street football is a form of sport which is organized in a spontaneous manner (self-organized) in streets, gardens, public spaces, etc. However, it is not deprived of rules and laws. This sport functions according to a compromise which signifies rules orally defined by the members of the sports group. In fact, before starting the match, the athletes gather and agree on the principles of the game. The compromise is presented as a contract resulting from the negotiation between them.

The rules are not stable. They change according to the situation and the context. Fundamentally, this consensus touches all the aspects of the game (rules, arbitration, time, team ${ }^{3}$, etc.). One of the young investigators of this case confirmed that "the rules of the game are inspired from official rules but adapted with the field in which we play. For example, this field is founded on a high ground. It makes us unable to play the corner kick by feet. So, we agree since the beginning of the match on playing by hands".

${ }^{3}$ Each neighbourhood has its trainings that are determined according to the age categories of the practitioners. We also find trainings for those whose ages rank from 12 and 14 years and 15 and 18. In fact, resorting to trainings occurs when there is match or tournament between neighborhoods. However, when there is a match just for fun and between the practitioners of the same neighborhood, the teams are made of practitioners that are present on the stadium's ground. 
Therefore, the compromise is a contract which is the result of a negotiation between the practitioners and the considered indicator. It changes according to the situation and context. Basically, the indicated consensus demonstrates the relation between the players and their context. However, the rules of the game are neither final nor rigid. They, on the contrary, vary following the number of players, the time reserved for the match and the nature of the space.

\subsubsection{The Adequacy of the Space}

Street football is a self-organized practice. It has a flexible relation to space. It is practiced in roads, parks, public gardens, in neighborhoods, and in the fields of primary and high schools. These are specific sport spaces that do not necessarily succumb to the norms of this sport. Also, players adapt these places to the nature of football. For example, the fields are surrounded by barriers, roofs, trees etc. The delimitation and the creation of these fields are always managed according to the negotiation between players.

The spaces of practice can be defined as "a spur of the moment that is fixed/attached temporarily" (Travet, Griffet, \& Therme, 1998). They can also be the result of a social construction with reference not only to the physical features of the area, but equally in line with the history of the spaces. Besides, the frequent visits of these spaces create a sense of belonging and possession for the players.

Our study demonstrates that spaces can be fixed, invariable, or changeable. We distinguish two big categories of fields.

$\checkmark$ The first one contains roads, space, parks, and parking like the field of game

$\checkmark$ The second category concerns equipped and more organized places such as stadiums and the fields of primary or high schools.

In all cases, the determination and the creation of these spaces are always done within the framework of the negotiation between the practitioners.

Multiple reasons drive players to choose football over other sports as a leisure activity in the streets. It is the most loved and the most popular. Moreover, it is the easiest to adapt to the streets. "The street football needs nothing but a ball", affirmed a young player. That's why street football is the most practiced sport by youngsters in Gafsa.

Football fields are vast and disorderly places. They are deprived of equipment and limited in multiple aspects. Goals can be drawn on walls, determined by stones or barriers. Also, players are not required to wear a sport uniform with a specific color for every team for distinction. The uniforms of players are different. They wear swimsuits, sweaters, tracksuits. Sometimes, they wear the uniforms of their favorite teams. Wearing a sport uniform is not a necessary condition to practice this sport.

\subsubsection{Invariable Practicing Time}

As opposed to institutional football, street football is played according to the activities of youngsters and especially their school timetables and the availability of 
the fields. In fact, the practicing time is the result of the negotiation process that can last for days. It is sometimes fixed when players meet in the field.

The results of the observations and the interviews allow us to distinguish two types of matches:

$\checkmark$ Previously organized matches: They are matches which take place between two neighborhoods or more. These matches are usually played on Saturday afternoon, on Sunday morning at $4 \mathrm{am}$ in summer, or on Sunday afternoon with teams usually formed of seven players. According to the observation, $68 \%$ of these matches are played by young people aged between 16 and 18 years old.

$\checkmark$ Occasional matches: These are the matches that take part in the field of neighborhoods, in front of garages, inside houses, in parking lots, in the middle of the roads, and in public gardens. They are instantly organized for fun and without a previous plan between people of different ages. These matches are played every Friday and Saturday afternoon, on Sunday morning and in the afternoon. They are almost daily played during the holidays. Also, the investigation showed us that the majority of these matches (75\%) are arranged by youngsters whose ages range from 11 to 15 years old.

Regardless of the type of the match, its duration is the result of the negotiation between the players. In previously organized matches, the players choose the duration of the match a few days before the game. However, the time is decided just before the game starts for the occasional matches. The time of the match can sometimes be determined according to the score. The teams can both determine the time (one hour, one hour and a half). Sometimes, the matches are played until the players get tired or until the sun sets.

\subsubsection{The Sport Team between Integration, Negotiation and Leadership}

Along with what characterizes it as a sport, street football is generally associated with a strong social integration capacity. This can be observed when analyzing the number of youngsters who practice this activity. Also, the number of matches organized daily in the fields of neighborhoods, the streets, and public gardens is substantial. The ability of street football to integrate young people is sustained by its openness. The large space of liberty it offers helps them create their games and organize their social time autonomously and independently. In this case, the sport team is a social framework that unites many categories of youngsters. Not only pupils, students, jobless, but also delinquents and handicapped youngsters can take part in this sport. It is not odd to see teams that include handicapped players. During our observation of the matches played in the neighborhood of RasElkaf, we noticed the regular participation of an 18-year-old teenager with Down syndrome. This teenager is known by the name "Cadra"4 He was pleased to play with his friends. This influenced his conduct in a very positive way. Youssef, one of the youngsters of this neighborhood, explained: "The solution we found for our buddy Haithem is to create a new position ${ }^{4}$ Cadra does mean a person of high standing and power. 
for him and we called it 'cadra'. Also, he can play for both teams at the same time without taking into consideration neither the faults he can commit, nor the goals he can score".

Like any other human group, there is an imposed internal organization. So, the notion of the captain or leader of the team is present. In street football, leaders change by time but usually keep the same characteristics of authority and efficiency.

\subsection{The Street Football as a Self-Organized Social System: Violence and Control of Violence}

Since street football is a non-organized social interaction, there is a high probability of facing problems and social perturbations. Problems such as conflicts between neighborhoods or pairs, social segregation, racial segregation, and sexism may arise. Although the players belong to different neighborhoods and social classes, we noticed that football games only have a slight degree of violence. The youngsters of these neighborhoods usually succeed to attain a very high level of peace and mutual respect.

\subsubsection{The Types of Violence Observed during the Matches and the Reactions against Aggression}

It is true that street sports are less protected than institutional sports since they lack official organization, but violence can take place even in official sport encounters. In fact, there are many forms of violence: physical, psychological, verbal and symbolic, etc., (Brohm, 1993; Dunning, 1986; Georges, 2001; Elias \& Dunning, 1986; Dunning, 1999). This is clearly reflected through the encounters between young football players in Gafsa. This study allowed us to distinguish between

$\checkmark$ Physical violence: violent acts through the use of the physical force or other tools such as stones, canes, etc.

$\checkmark$ Verbal violence: violent acts characterized by shouting, insults, abusive and vulgar words, demeaning, etc.

$\checkmark$ Symbolic violence: violence related to signs, gestures, or facial expressions. Figure 1 shows that street football is not free of forms of violence.

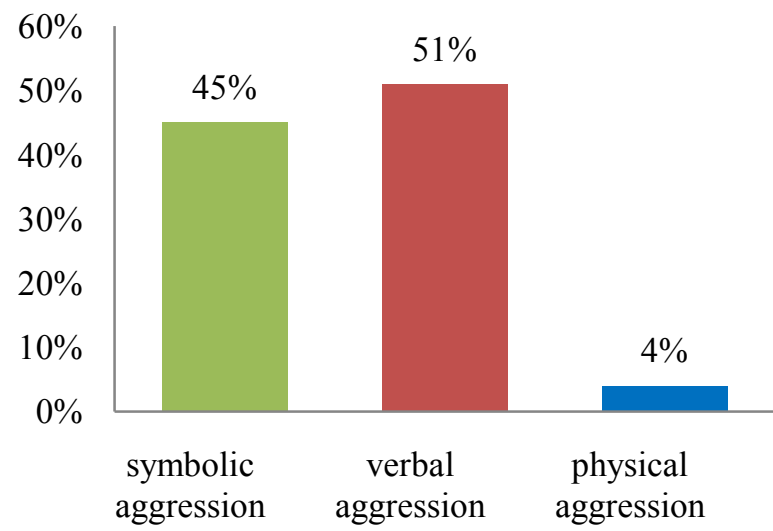

Figure 1. Breakdown of types of aggression observed during matches. 
As we mentioned earlier, football players' violent conduct can only generate harsh and aggressive reactions. Sometimes, this kind of behavior can go unnoticed. In general, violence acts can have diverse responses. The reactions can be symbolic, verbal, physical or passive. In fact, an act of violence can even have more than one response.

Table 2 shows that street football incites youngsters to manage violence. ${ }^{5}$ It is part of the match rules that have to be respected.

\subsubsection{Violence Management and Risk Tolerance}

As a self-organized social system without official organizational institutions, street football is prone to a considerably high degree of risk. Consequently, we consider the street sport activities as risky ones. The practice of these activities forms a "deliberate risk-taking" according to Patrick PerettiWatel who thinks that the players "knowingly challenge the danger" (Peretti Watel, 2010).

Young football players are exposed to multiple risks. Street football is practiced in the streets, gardens, and unsafe and disorderly fields. The sport is generally organized by words of mouth in unsafe and disorderly fields. In most of the cases, the soil on which players play does not comply to the basic security norms. It is covered in stones, holes, and broken glass. The fields are sometimes located on the edge of roads. This increases the risk of road accidents. Ahmed, a young guy aged 16, was the victim of a road accident (five years ago) while playing a match in a field on the edge of the road. This guy was hit by a heavy truck while trying to catch the ball. That accident caused him a face deformation along with right hand and foot disabilities. Many dangers are related to the conditions of the field. Mainly, these dangers concern sports fields in high schools or primary schools or any other restricted area. The access to these fields represents a great risk-taking. Thus, risk-taking has become a prerequisite for the players to achieve their ambitions.

Despite the frequency of violence acts observed in the matches, we noticed that most of the games ended peacefully. Only four of 72 matches observed (less than 6\%) were stopped because of violence. In spite of the small size of the fields in which the games were observed, with just $124 \mathrm{~m}^{2}$ for the single player (versus $324 \mathrm{~m}^{2}$ in the normal fields), the degree of violence is reduced. This can be explained by the fact that violence is a risk that deprives those youngsters of practicing their favorite activity. That's why they find multiple reasons to maintain peace and tranquility in their social relations.

Table 2. The types of assaults observed and their reactions.

\begin{tabular}{cccccc}
\hline \multirow{2}{*}{ Types of assault } & \multirow{2}{*}{ Percentages } & \multicolumn{4}{c}{ Types of reactions } \\
\cline { 3 - 6 } & & Neutral & symbolic & verbal & physical \\
\hline verbal aggression & $51 \%$ & $59 \%$ & $18 \%$ & $22 \%$ & $1 \%$ \\
Symbolic attacks & $45 \%$ & $57 \%$ & $23 \%$ & $20 \%$ & $0 \%$ \\
Physical aggression & $4 \%$ & $57 \%$ & $6 \%$ & $26 \%$ & $11 \%$ \\
\hline
\end{tabular}

${ }^{5}$ The statistical analysis revealed that there is significant difference between mastered aggressions and non mastered aggressions for $p=0$ ( $\mathrm{Chi}^{2}$ of Pearson: 124,802; $\left.\mathrm{dl}=6 ; p=0.000000\right)$. 
In this case, one of the youngsters said: "In street football, violence is part of the game. In fact, a good match is an intense match. This intensity is necessarily followed by violence. It can be symbolic, verbal or rarely physical. That is why, I maintain my self-control whenever I hear a violent expression or whenever somebody provokes me with a gesture. What counts for me is to continue the match till the end. That is why I attempt to avoid any confrontation."

\section{Conclusion}

Far away from gyms, outside stadiums and without either appropriate equipment or adhesion card, sports have a strong ability to modify its own rules. It can liberate itself from the constraints of official encounters and overcome its typical definition that has been untouched in for a long time. Street football, the center of our study, succeeded to modify the basis of the institutional football. In its institutional form, football requires victory at any cost. Winning highlights other parameters that can characterize sports in general and football in particular. Sharing, integration, self-confidence, social connection, creativity, compromise, and living together are instances of these parameters.

Street football is an informal space that finds its sport identity through compromises and agreements between actors. They coordinate with each other and fix negotiation methods that do not only determine the rules for the game but also the field, the equipment, the engines, etc. In addition, as a competitive sport in which victory and the desire to beat others are important, street football is not excluded from acts of violence and aggression. On the contrary, violence is a principal aspect of this field. It may take various forms. It can be symbolic (signs, gestures, facial expressions, humiliations, etc.), verbal (yelling, insults, abusive and vulgar words, etc.), or physical (beating, pushing, etc.). Despite its non-institutional nature, the majority of the acts of violence were responded by silence. Aggressive behavior was not really witnessed. The players proved a strong ability to manage violence despite the tension that reigns upon their encounters.

According to Elias and Dunning (Elias \& Dunning, 1986), violence management during sport competitions is explained by the institutional aspect of the sport. Generally, the regulations and the arbitration take the form of a compromise resulting from the negotiations between the participants during their informal encounters. This helps ensure a certain level of peace and cohesion that allows the match to smoothly progress.

\section{Conflicts of Interest}

The authors declare no conflicts of interest regarding the publication of this paper.

\section{References}

Brohm, J. M. (1992). Political Sociology of Sport (p. 89). Paris: PUN. 
Brohm, J. M. (1993). Sports Packs (p. 11). Paris: L'Harmattan.

Dunning, E. (1986). Social Link and Violence in Sport. In N. Elias, \& E. Dunning (Eds.), Op-Cit (pp. 311-312). Paris: Fayard.

Dunning, E. (1999). Sport Matters: Sociological Studies of Sport, Violence and Civilization. Abingdon-on-Thames: Routledge.

Duret, P. (2008). Sociology of Sport. Collection “Que Sais-Je?”, Paris: PUF.

Elias, N., \& Dunning, E. (1986). Sport and Civilization: Mastered Violence. Paris: Fayard.

Gasparini, W., \& Marchiset, G. V. (2008). Neighborhood Sport: Social Practices and Public Policies. Paris: PUF.

Georges, V. (2001). Préface. In D. Bodin (Ed.), Sports and Violences. Paris: Editions du conseil de l'Europe.

Henri-Irénée Marrou in Dominique Baillet (2001). Les grands thèmes de la sociologie du sport (p. 15). Paris: L'Harmattan.

Mauss, M. (1997). Essai sur le don. Forme et raison de l'échange dans les sociétés archaïques. In Sociologie et anthropologie (p. 274). Paris: PUF.

Marchiset, G. V. (2003). Street Sports and Sports Powers: Conflicts and Changes in the Local Space. Paris: PUF-Comtoises.

Parlebas, P. (2012). Sport and Motor Action in the Social Sciences. In G. V. Marchiset, \& A. Tatu-Colasseau (Eds.), Sociology of Sport: Francophone Analysis and Circulation of Knowledge (p. 178). Paris: L'Harmattan.

Peretti Watel, P. (2010). The Society of Risk (p. 101). Paris: La Découverte.

Parlebas, P. (1986). Elément de sociologie du sport (p. 248). Paris: PUF.

Travet, M., Griffet, J., \& Therme, P. (1998). Football des rues et des stades. Les Annales de la Recherche Urbaine, 79, 113. https://doi.org/10.3406/aru.1998.2183 